\title{
Atmospheric pressure dielectric barrier discharge for the remediation of soil contaminated by organic pollutants
}

\author{
C. A. Aggelopoulos ${ }^{1}$
}

Received: 17 September 2015/Revised: 31 December 2015/ Accepted: 3 May 2016/Published online: 11 May 2016

(C) Islamic Azad University (IAU) 2016

\begin{abstract}
The remediation of soil, contaminated by organic pollutants, in a cylinder-to-plane dielectric barrier discharge reactor at atmospheric air pressure was reported. Two model organic pollutants were selected; a solid pollutant (2,6-dichloropyridine) and a liquid pollutant ( $n$-dodecane). The effects of the contaminant's initial concentration and state, the energy consumption, and the soil type on the pollutant removal efficiency were investigated. To that scope, various contaminated samples of both quartz sand and loamy sandy soil were treated by plasma for various treatment times and initial 2,6-dichloropyridine/ $n$-dodecane concentrations. The results revealed that (1) the removal efficiency of 2,6-dichloropyridine was higher compared to that of $n$-dodecane at a given plasma treatment time and (2) the removal efficiency increased with the energy density increasing, but decreased as the soil heterogeneity, organic matter and pollutant concentration were enhanced. The main removal mechanism proposed is the evaporation of pollutant molecules coupled with their oxidation by plasma species in the gas and solid/liquid phase.
\end{abstract}

\section{A. Aggelopoulos}

caggelop@iceht.forth.gr

1 Foundation for Research and Technology Hellas - Institute of Chemical Engineering Sciences, Stadiou Str., Platani, 26504 Patras-Rio, Greece
Keywords Active species · Degradation efficiency · Non-thermal plasma Pollutant oxidation .

Soil remediation

\section{Introduction}

Soil contamination by organic pollutants such as pesticides, pharmaceuticals, poly-aromatic hydrocarbons (PAHs), chlorinated solvents and total petroleum hydrocarbons (TPHs) is strongly related to social, economic and environmental sustainability, and it is considered as a significant threat for human health through the food chain. Soil pollution by organic pollutants typically arises from the extensive use of pesticides, direct discharge of chemical and industrial wastes to the soil, leaching of wastes from landfills and leakages due to the rupture of underground storage tanks (Mirsal 2008).

Soil contaminated with organic pollutants is commonly treated by conventional technologies, such as incineration, steam injection (Triplett Kingston et al. 2010; Tzovolou et al. 2011), soil vapor extraction and bioremediation (Lladó et al. 2013) where oxygen or nutrient amendments are injected through the soil. Most of these methods are highly energy-consuming (e.g., incineration) or have low removal efficiency in low permeability zones (e.g., soil vapor extraction, steam injection) (Nilsson et al. 2011; Carroll et al. 2012). The latter is due to the high permeability fluctuation of mineral soils (sand/clay/silt) that leads to preferential flow of the flushing remedial fluids through the high permeability soil layers (Aggelopoulos and Tsakiroglou 2008, 2009). On the other hand, bioremediation is a time-consuming process and the activity of the microorganisms is strongly related to several parameters, such as soil humidity, soil 
temperature and pollutant toxicity. Alternative remediation techniques such as smoldering combustion, electrokinetic remediation (Pironi et al. 2011; López-Vizcaíno et al. 2014; Bocos et al. 2015) and chemical oxidation (e.g., ozonation, $\mathrm{H}_{2} \mathrm{O}_{2}$, Fenton's reagent) have also been proposed (Yu et al. 2007; Cai et al. 2012; Pardo et al. 2015). However, these techniques are not only energyconsuming but also in some cases expensive chemical reagents are needed. Therefore, the development of efficient, cost-effective, rapid and environmental friendly methods for the removal of organic pollutants from soils is crucial.

Non-thermal plasmas (NTPs) are regarded as promising advanced oxidation processes (AOPs) for the sustainable and efficient removal of organic pollutants from wastewater (Ognier et al. 2009; Hijosa-Valsero et al. 2013; Iya-Sou et al. 2013; Jamróz et al. 2014; Magureanu et al. 2015; Stratton et al. 2015) and polluted gas (Ostapczuk et al. 2008; Malik et al. 2011; Jolibois et al. 2012; Bao et al. 2014; Zhang et al. 2015). During the last few years, they have started to be examined for soil remediation (Wang et al. 2010; Lou et al. 2012; Ognier et al. 2014; Aggelopoulos et al. 2015a). During NTP discharge at atmospheric pressure, high-energy electrons are produced, providing thus space charge and highly reactive oxidative species including active radicals $(\mathrm{O}$, $\mathrm{OH}, \mathrm{H}$ radicals) and active molecules $\left(\mathrm{O}_{3}, \mathrm{NO}_{\mathrm{x}}, \mathrm{H}_{2} \mathrm{O}_{2}\right)$. All these species, due to their high oxidation potentials, along with the physical energies generated from plasma discharge (e.g., UV radiation and heating) are capable of oxidizing organic compounds with extremely high reaction rates (Locke et al. 2006). Regarding soil remediation studies, pulsed corona and dielectric barrier discharge (DBD) plasma have been used for the removal of solid or liquid organic pollutants at atmospheric pressure (Redolfi et al. 2010; Wang et al. 2011a, b; Lu et al. 2014; Aggelopoulos et al. 2015b), but no attention has been paid on the comparison of the removal efficiency between solid and liquid pollutants.

In this paper, the remediation of soil layers contaminated with one solid (i.e., 2,6-dichloropyridine) and one liquid organic pollutant (i.e., $n$-dodecane) was studied in a cylinder-to-plane DBD reactor, under atmospheric air pressure. 2,6-Dichloropyridine $\left(\mathrm{C}_{5} \mathrm{H}_{3} \mathrm{Cl}_{2} \mathrm{~N}\right)$ is widely used as an intermediate for manufacturing synthetic organics, pharmaceuticals, fungicides, herbicides and as a catalyst for phase transfer; $n$-dodecane $\left(n-\mathrm{C}_{12}\right)$ is a liquid alkane hydrocarbon which is found in kerosene-based fuels, and is also used as a solvent and distillation chaser. The plasma discharge experiments were conducted at various treatment times and initial pollutant concentrations on two soil types differing with respect to the degree of micro-heterogeneity. In this manner, the removal efficiency of solid and liquid organic pollutants, which have the same boiling point, was compared and correlated with the energy consumption, initial pollutant concentration and soil type. Finally, the main mechanisms of organic pollutant degradation were discussed.

\section{Materials and methods}

\section{Materials}

2,6-Dichloropyridine (purity $>98 \%$ ) and $n$ - $\mathrm{C}_{12}$ (purity $>95 \%$ ) were purchased from Sigma Aldrich and Merck, respectively (Table 1). Several soil samples were artificially polluted by 2,6-dichloropyridine or $n$ - $\mathrm{C}_{12}$. The contamination of the soil samples at various pollutant initial concentrations (i.e., $0.5,5,50 \mathrm{~g} / \mathrm{kg}$-soil) was carried out by mixing pre-weighted soil samples with pollutant solutions in acetone as described in a previous study (Aggelopoulos et al. 2015a).

Two different soil types were examined; a commercial quartz sand with narrow grain size distribution (homogeneous sand) and a loamy sandy soil with broad grain size distribution collected from the region of Western Greece. The latter had a content of $83 \%$ sand, $4 \%$ silt and $13 \%$ clay. The main properties of these two porous media are presented in Table 2.

\section{Dielectric barrier discharge (DBD) plasma reactor for soil treatment}

The experimental setup along with the cylinder-to-plane DBD reactor used for the plasma treatment of contaminated soil samples is depicted in Fig. 1. The alternating (AC) driving voltage was supplied by a high voltage power supply (40 kHz, 0-20 kV peak-to-peak), and it was ranged from 12 to $14 \mathrm{kV}$ for all experiments. The applied high voltage was measured with a Tektronix P6015 probe, and the circuit current was calculated by measuring the voltage between the ground electrode and an equivalent resistance of $50 \Omega$. Their waveforms were continuously monitored by a LeCroy LT 342, $500 \mathrm{MHz}$ digital oscilloscope (Fig. 1a), and the discharge power $P$ was calculated approximately by integrating the instantaneous voltage and current over two periods of the applied voltage. 
Table 1 Pollutant properties

\begin{tabular}{llll}
\hline Pollutant & Molecular weight $(\mathrm{g} / \mathrm{mol})$ & Boiling point $\left({ }^{\circ} \mathrm{C}\right)$ & Vapor pressure \\
\hline $\mathrm{C}_{5} \mathrm{H}_{3} \mathrm{Cl}_{2} \mathrm{~N}$ & 147.99 & 211 & Not available \\
$n-\mathrm{C}_{12}$ & 170.34 & $214-218$ & $18 \mathrm{~Pa}\left(25{ }^{\circ} \mathrm{C}\right)$ \\
\hline
\end{tabular}

Table 2 Soil properties

\begin{tabular}{lllc}
\hline Soil & Grain size distribution & Porosity & Permeability $\left(\mathrm{m}^{2}\right)$ \\
\hline Quartz sand & $125-250(\mu \mathrm{m})$ & 0.40 & $25 \times 10^{-12}$ \\
Loamy sandy soil & $<2 \mu \mathrm{m}-2 \mathrm{~mm}^{\mathrm{a}}$ & 0.45 & $385 \times 10^{-15}$ \\
\hline
\end{tabular}

a $50 \mu \mathrm{m}<d_{\mathrm{g}}<2$ mm: $83 \% ; 2 \mu \mathrm{m}<d_{\mathrm{g}}<50 \mu \mathrm{m}: 4 \%$; $d_{\mathrm{g}}<2 \mu \mathrm{m}: 13 \%$

The biased electrode of the DBD reactor (Fig. 1b) was a stainless steel cylinder ( $80 \mathrm{~mm}$ length and $13 \mathrm{~mm}$ diameter) covered by a 4-mm-thick alumina tube acting as the dielectric barrier of the discharge. The grounded electrode was a stainless steel plate $(97 \mathrm{~mm} \times 85 \mathrm{~mm}$, thickness: $10 \mathrm{~mm}$ ) where $4 \mathrm{~g}$ of contaminated soil samples, about $1 \mathrm{~mm}$ thick, were spread uniformly. The grounded electrode was supported on a belt conveyor which was induced to motion by a motor at a constant velocity of $40 \mathrm{~mm} / \mathrm{min}$ and therefore the time needed to treat the soil covering the grounded electrode was $2.5 \mathrm{~min}$. In the present study, the distance between the alumina dielectric and the grounded electrode was kept constant at $2 \mathrm{~mm}$. Bottled dry air was injected at atmospheric pressure in the reactor at a constant flow rate $1 \mathrm{l} / \mathrm{min}$ which was controlled by a gas flow meter (Fig. 1a).

The soil treatment time was controlled by adjusting the number of times the whole surface of the soil was treated (the belt conveyor completed a round) and varied from 2.5 to $34 \mathrm{~min}$. Control experiments (i.e., ventilation without plasma) were also performed, confirming that no pollutant was removed due to air ventilation. All experiments were conducted in duplicates with the standard deviation of experimental data being negligible.

\section{Chemical analysis of soils}

After the plasma treatment, the remaining 2,6-dichloropyridine and $n-\mathrm{C}_{12}$ were extracted from the soil samples using methanol and dichloromethane as extraction solvents, respectively. Each soil sample $(4 \mathrm{~g})$ was added to $10 \mathrm{ml}$ of solvent, and the mixture was shaken for $24 \mathrm{~h}$ on an overhead shaker at a speed of $12 \mathrm{rpm}$. After filtration through $0.45 \mu \mathrm{m}$ PTFE filters, the soil extracts were injected in a Shimadzu GC-FID (GC 2014) equipped with a fused silica capillary column $(50 \mathrm{~m} \times 0.2 \mathrm{~mm} \mathrm{i.d} \times 0.5 \mu \mathrm{m} \quad$ film thickness, PETROCOL, Supelco) to quantify the residual concentration of organic pollutants (2,6-dichloropyridine and $\left.n-\mathrm{C}_{12}\right)$ in the soil.

For the 2,6-dichloropyridine analysis, high-purity helium was used as a carrier gas at a constant flow rate of $29.2 \mathrm{ml} / \mathrm{min}$. The sample injection volume was $1 \mu \mathrm{l}$, and the split ratio was fixed at 1:20. The injector and detector temperature were set to 270 and $300{ }^{\circ} \mathrm{C}$, respectively. The oven temperature was kept at $100{ }^{\circ} \mathrm{C}$ for $1 \mathrm{~min}$, ramped up at a rate of $30{ }^{\circ} \mathrm{C} / \mathrm{min}$ to $180{ }^{\circ} \mathrm{C}$ and subsequently ramped up at a rate of $40{ }^{\circ} \mathrm{C} / \mathrm{min}$ to $210^{\circ} \mathrm{C}$ where it was kept constant for $1 \mathrm{~min}$. For $n$ - $\mathrm{C}_{12}$ analysis, the flow rate of helium was $15.9 \mathrm{ml} / \mathrm{min}$ and the split ratio was fixed at $1: 15$. The injector and detector temperature were set to 250 and $280^{\circ} \mathrm{C}$, respectively. The oven temperature was kept at $40{ }^{\circ} \mathrm{C}$ for $10 \mathrm{~min}$, ramped up at a rate of $1.1^{\circ} \mathrm{C} / \mathrm{min}$ to $114{ }^{\circ} \mathrm{C}$ and subsequently ramped up at a rate of $1.7 .{ }^{\circ} \mathrm{C} /$ min to $250^{\circ} \mathrm{C}$ where it was kept constant for $15 \mathrm{~min}$. Control experiments in untreated soil samples showed that the 2,6-dichloropyridine and $n$ - $\mathrm{C}_{12}$ recovery from soil was greater than 95 and $99 \%$, respectively.

\section{Results and discussion}

\section{Effects of energy density and initial pollutant concentration on degradation efficiency}

Plasma discharge experiments were performed at various treatment times ranged from $\sim 2.5$ to $\sim 34$ min with the corresponding energy density, $E_{\mathrm{D}}$, ranging from 840 to $12650 \mathrm{~J} / \mathrm{g}$-soil, depending on the mass of the soil treated and the power of the DBD according to Eq. (1):

$E_{\mathrm{D}}=P_{\text {mean }} \times t / m$

where $P_{\text {mean }}$ is the calculated mean power of the DBD ( $\sim 25 \mathrm{~W}$ in this study), $t$ is the treatment time (s), and $m$ is the mass of the soil sample $(\mathrm{g})$. 
Fig. 1 Schematic diagram of a the experimental setup used to treat the contaminated soils; b details of the DBD reactor (a)
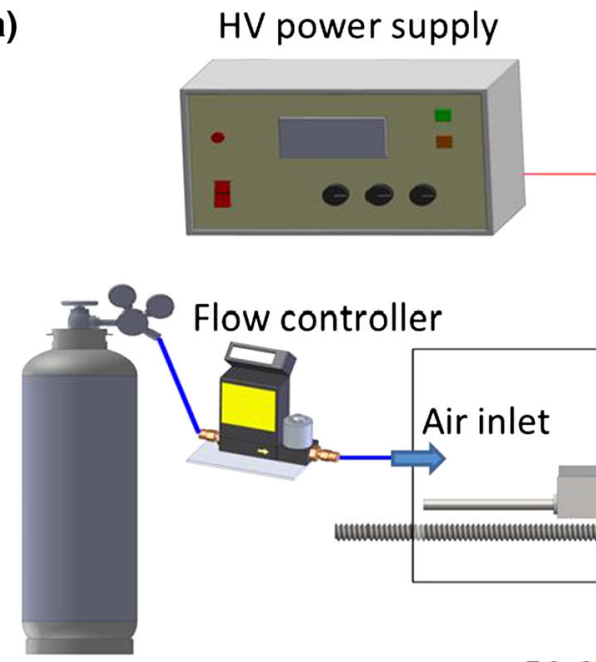

Bottled air

\section{Flow controller}

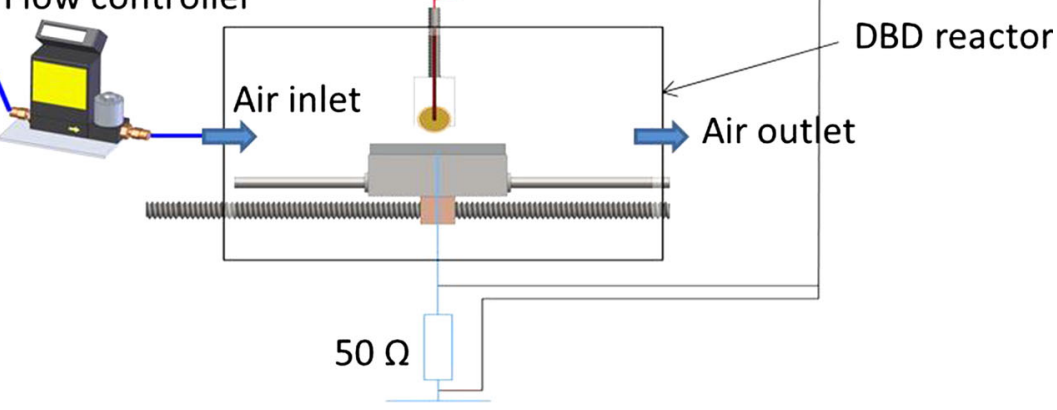

(b)

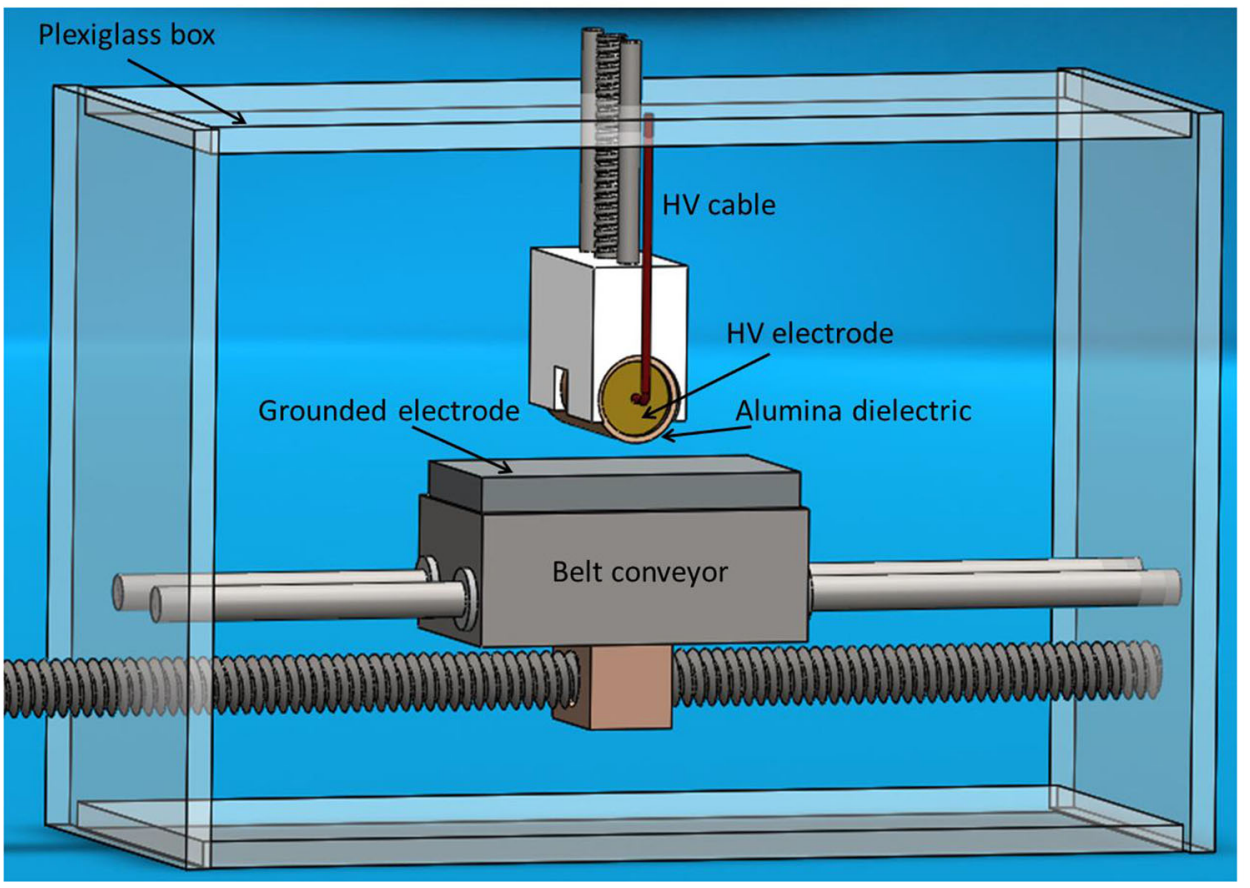

In Fig. 2, the 2,6-dichloropyridine removal efficiency is shown as a function of the treatment time and energy density for a loamy sandy soil sample at various initial pollutant concentrations. The 2,6-dichloropyridine removal efficiency was increased rapidly at shorter treatment times which correspond to low energy densities. However, the removal rate becomes gradually slower tending asymptotically to reach a constant value, in agreement with recently published results (Lou et al. 2012; Aggelopoulos et al. 2015a; Aggelopoulos et al. 2015b). At shorter treatment times, where the 2,6-dichloropyridine concentration in the soil is high, the produced plasma reactive species reacted 

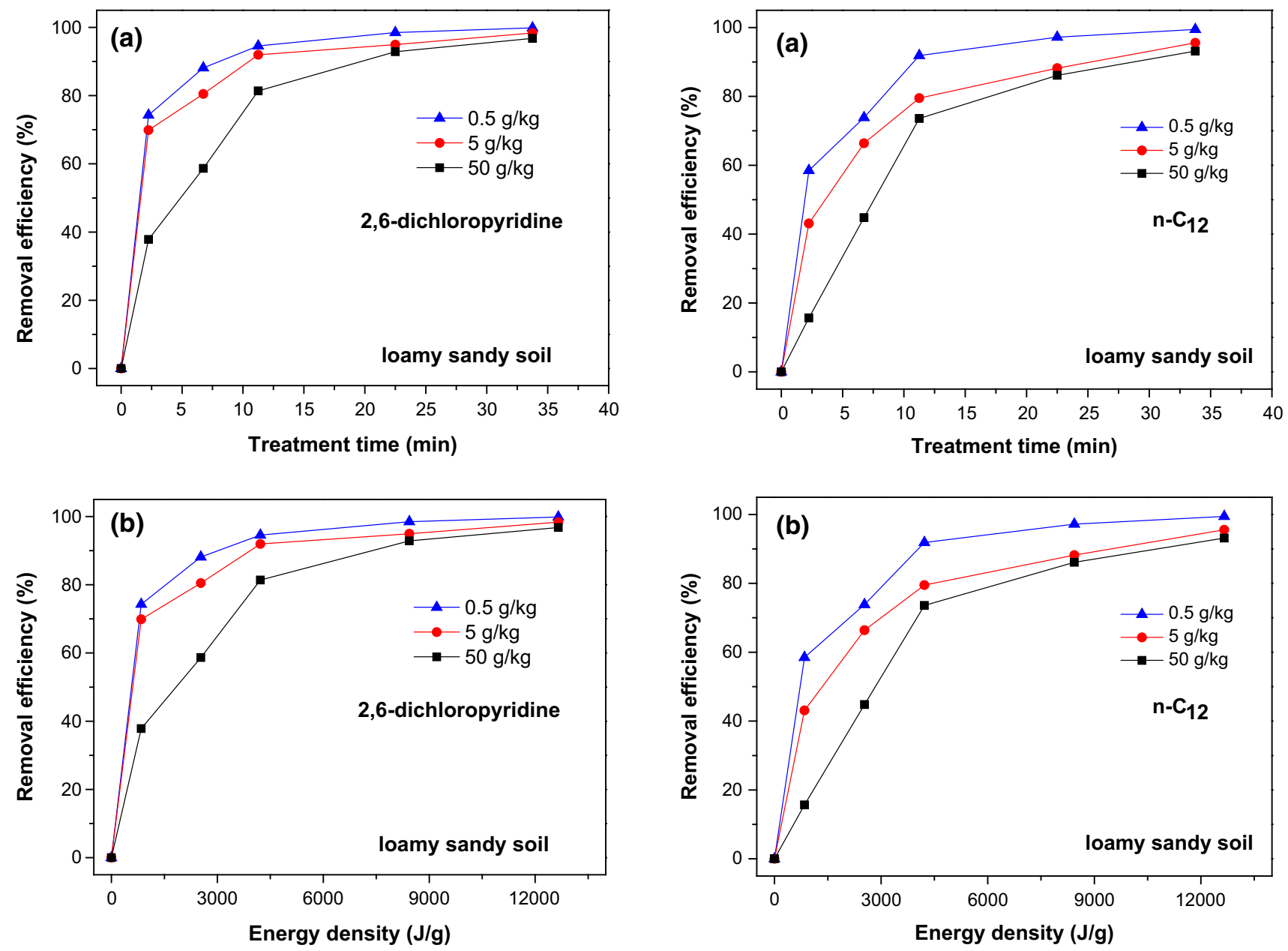

Fig. 2 The 2,6-dichloropyridine removal efficiency as a function of the a plasma treatment time and $\mathbf{b}$ plasma energy density for various initial 2,6-dichloropyridine concentrations

Fig. 3 The $n$-dodecane removal efficiency as a function of the a plasma treatment time and $\mathbf{b}$ plasma energy density for various initial $n$-dodecane concentrations

highly with the 2,6-dichloropyridine molecules and the reaction was fast. At longer treatment times, the plasma active species reacted less frequently with the 2,6dichloropyridine molecules resulting to a slower reaction. This observation is consistent, considering that (1) a sufficient amount of 2,6-dichloropyridine molecules had already been removed and (2) intermediate products produced during the 2,6-dichloropyridine oxidation compete with the 2,6-dichloropyridine molecules for reactions with the plasma active species (Wang et al. 2014; Aggelopoulos et al. 2015b).

Regarding the effect of initial pollutant concentration, it becomes apparent that the 2,6-dichloropyridine removal

efficiency decreased as the initial 2,6-dichloropyridine concentration increased (Fig. 2) in agreement with published data in the literature (Lou et al. 2012; Aggelopoulos et al. 2015a). After 7 min of plasma treatment, 88, 80 and $59 \%$ of 2,6-dichloropyridine was removed at initial concentrations of $0.5,5$ and $50 \mathrm{~g} / \mathrm{kg}$, respectively (Fig. 2a). It should be mentioned, however, that the 2,6-dichloropyridine degradation was almost complete after $34 \mathrm{~min}$ of plasma treatment, regardless of its initial concentration (Fig. 2a).

In Fig. 3, the $n-\mathrm{C}_{12}$ removal efficiency is presented as a function of the treatment time and energy density for a loamy sandy soil sample at various initial pollutant con- 

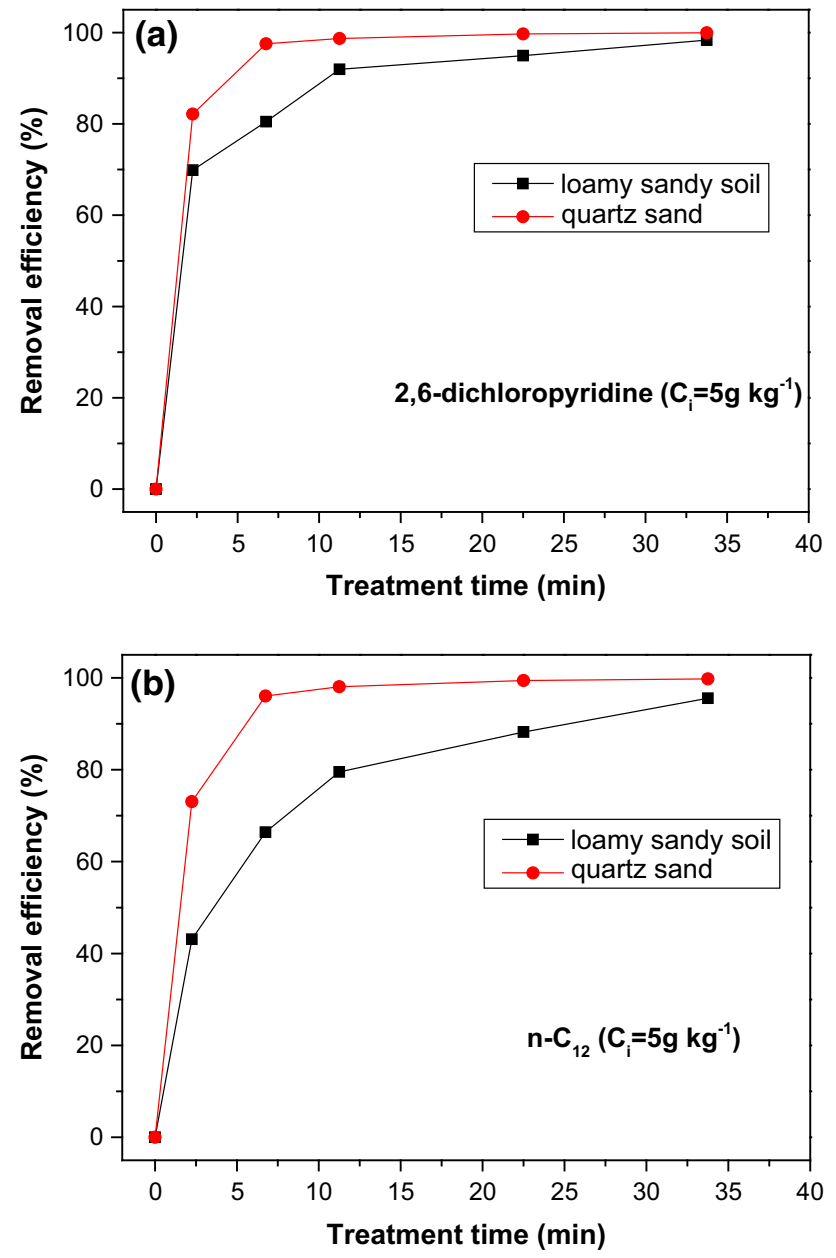

Fig. 4 Effect of soil type on the pollutant removal efficiency a 2,6dichloropyridine; b $n$-dodecane

centrations. The same behavior (as in the case of 2,6dichloropyridine) was observed regarding the effect of both treatment time and energy density on the $n-\mathrm{C}_{12}$ removal efficiency. In particular, the removal efficiency of $n-\mathrm{C}_{12}$ increased more rapidly over short treatment periods (low energy densities) than in long treatment periods (high energy densities). Furthermore, the effect of the initial pollutant concentration on the pollutant removal efficiency was confirmed, since it is apparent that the $n$ - $\mathrm{C}_{12}$ degradation efficiency decreased as its initial concentration in soil was increased from 0.5 to $50 \mathrm{~g} / \mathrm{kg}$ (Fig. 3).

\section{Effect of soil type on pollutant degradation}

The effect of soil characteristics on the pollutants $(2,6$ dichloropyridine $/ n-\mathrm{C}_{12}$ ) degradation efficiency is depicted

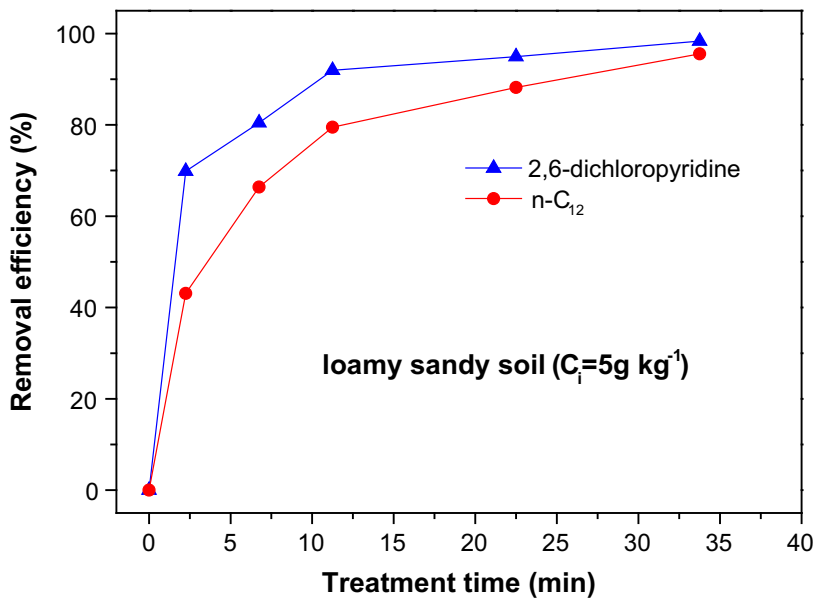

Fig. 5 The comparison between the removal efficiency of 2,6dichloropyridine and $n$-dodecane

in Fig. 4. For an initial pollutant concentration $5 \mathrm{~g} / \mathrm{kg}$-soil, the pollutant removal efficiency was increased more rapidly for the quartz sand compared to the loamy sandy soil in agreement with published results (Wang et al. 2014). After 7 min of treatment, the 2,6-dichloropyridine removal efficiency for quartz sand and loamy sandy soil was 98 and $80 \%$, respectively (Fig. 4a). Similarly, the $n$-C $\mathrm{C}_{12}$ removal efficiency for quartz sand and loamy sandy soil was 96 and $66 \%$, respectively (Fig. 4b). It is noteworthy, that after $34 \mathrm{~min}$ of treatment, the removal efficiency of both pollutants was almost complete and independent of soil type (Fig. 4).

The variance of the pollutant removal efficiency between the quartz sand and the loamy sandy soil could be attributed to the different properties of the two soil types. These two soil types varied in terms of the organic matter and the particle/pore sizes, given that (1) there is no organic matter in the commercial quartz sand unlike the loamy sandy soil collected from the region of Western Greece and (2) the quartz sand has a narrower grain/pore size distribution compared to the loamy sandy soil. The loamy sandy soil organic matter not only could compete with the pollutants for reactions with the active species produced by plasma, but could also adsorb the organic pollutants slowing thus the reactions between the active species and the latter (Wang et al. 2014). Moreover, the penetration of the produced active plasma species and the pollutant transfer in the quartz sand is expected to proceed uniformly in accordance with its narrow pore size distribution, as opposed to the loamy sandy soil, where the smaller air/pollutant interfacial area of pollutant-occupied pores may lead to weaker pollutant removal rates and 


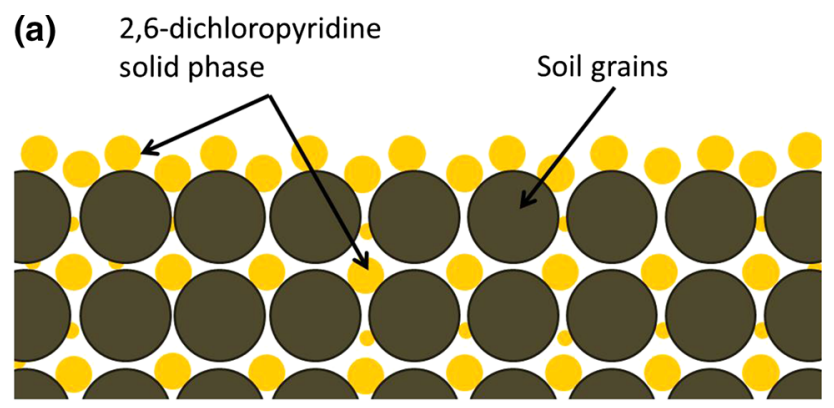

(b) n-dodecane liquid phase

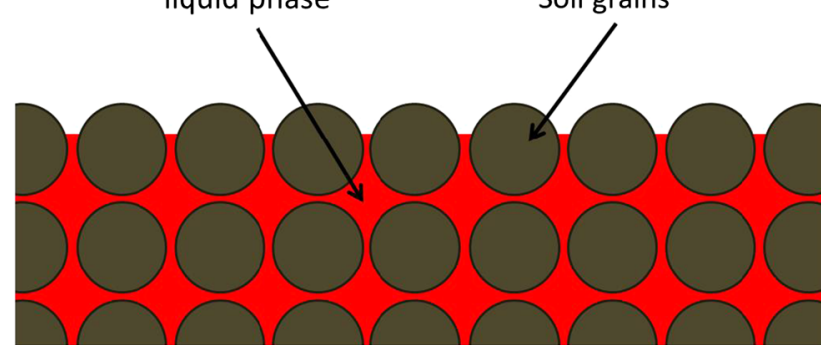

Fig. 6 Contaminated soil by a 2,6-dichloropyridine (solid pollutant); b $n$-dodecane (liquid pollutant)

subsequently to lower pollutant removal efficiency (Aggelopoulos et al. 2015a).

\section{Effect of the pollutant state on the pollutant degradation}

After $\sim 2.5 \mathrm{~min}$ of plasma treatment, the removal efficiencies of 2,6-dichloropyridine and $n$ - $\mathrm{C}_{12}$ were 70 and $43 \%$, respectively (Fig. 5), whereas after $\sim 7 \mathrm{~min}$ of treatment they were 80 and $66 \%$ accordingly. It is therefore evident that the removal efficiency of 2,6dichloropyridine was always higher compared to that of $n$ $\mathrm{C}_{12}$ at a given plasma treatment time. Given that the vapor pressure of 2,6-dichloropyridine is not available (see Table 1), this difference could be attributed to the following reasons. Assuming higher vapor pressure of 2,6dichloropyridine compared to that of $n-\mathrm{C}_{12}$, the evaporation percentage, due to plasma temperature, would be also higher (see discussion below), leading to faster 2,6dichloropyridine removal from soil layers. Conversely, in the case of similar or lower 2,6-dichloropyridine vapor pressure compared to that of $n-\mathrm{C}_{12}$, the higher 2,6dichloropyridine oxidation rate could be attributed either to its lower molecular mass (Table 1) leading to lower energy requirements for the corresponding oxidation reactions or to the solid state of 2,6-dichloropyridine molecules. In particular, after acetone evaporation (it is reminded that soil contamination was carried out by mixing soil samples with pollutant solutions in acetone), a fraction of the initial solid 2,6-dichloropyridine molecules remained on the soil surface (confirmed by naked-eye observations) in contrast to the liquid $n$ - $\mathrm{C}_{12}$ molecules entirely placed into soil pores (Fig. 6). Plasma active species come in contact faster with the fraction of initial 2,6-dichloropyridine spread on the soil surface increasing thus its overall degradation rate. Furthermore, the air flow and the subsequent penetration of the active species inside the soil pores were hindered in the $n$ - $\mathrm{C}_{12}$-contaminated soil, since the volume of each $n$ - $\mathrm{C}_{12^{-}}$ polluted pore was completely occupied by the liquid pollutant (Fig. 6b), whereas each 2,6-dichloropyridine-polluted pore was partially occupied by the solid pollutant (Fig. 6a).

\section{Pollutant degradation mechanism}

During plasma treatment, the temperature of the sand could reach more than $200{ }^{\circ} \mathrm{C}$ (Ognier et al. 2014), due to the high-energy electron impacts with the background gas molecules. At such temperatures, a significant amount of the pollutant evaporates, allowing thus its subsequent oxidation in the gas phase by the active plasma species. Given that the boiling points of 2,6-dichloropyridine and $n-\mathrm{C}_{12}$ are 211 and $218{ }^{\circ} \mathrm{C}$, respectively, a high percentage of both pollutants is expected to evaporate.

In addition, some intermediate products were generated directly from the initial pollutant oxidation in the soil, given that new peaks were detected from GC-FID for both pollutants after $\sim 7 \mathrm{~min}$ of plasma treatment (data not shown here). Regarding the $n$ - $\mathrm{C}_{12}$ oxidation by $\mathrm{DBD}$ plasma, the intermediates in soil have been identified as alcohols and ketones of the same number of carbon atoms (i.e., 6-dodecanol, 6-dodecanone, 3-dodecanol, 2-dodecanol, 3-dodecanone, 2-dodecanone, etc.) (Aggelopoulos et al. 2015b), whereas intermediates of 2,6-dichloropyridine oxidation are not available. It has been reported that the intermediates produced from the ozonation or plasma oxidation of chlorinated molecules (e.g., PCP) were less toxic than the initial pollutant (Anotai et al. 2007; Wang et al. 2010). However, a detailed intermediates identification and toxicity tests is needed to be further study. It is noteworthy that at the end of the plasma treatment, the produced intermediates of both pollutants were almost completely removed through evaporation and/or successive oxidation to $\mathrm{CO}$ and $\mathrm{CO}_{2}$, given that the new peaks detected from GC-FID (after 7 min of plasma treatment) 
were almost completely disappeared after $34 \mathrm{~min}$ of plasma treatment.

In order to estimate the percentage of pollutant evaporating, the carbon content of the intermediates, produced from $n-\mathrm{C}_{12}$ oxidation in soil after $7 \mathrm{~min}$ of plasma treatment, was measured using a semi-quantitative approach (Redolfi et al. 2010) and found to be $\sim 20 \%$ of the carbon content of the initial pollutant, in agreement with recent published results (Aggelopoulos et al. 2015a). It is noteworthy that this percentage may be higher, since no soil samples were collected and analyzed in the time range 2.5-7 min, where the carbon content of intermediates could be $>20 \%$. In other words, less than $80 \%$ of the initial $n-\mathrm{C}_{12}$ was evaporated with the rest $>20 \%$ being oxidized inside the soil pores. 2,6-Dichloropyridine evaporation percentage cannot be estimated due to unknown identity of its intermediates in soil. In order to measure the percentage of evaporation, a thorough on-line analysis of the exhaust gases is required. Based on the former calculations, it is suggested that the main pollutant degradation mechanism is evaporation coupled with the pollutants' oxidation in the gas and liquid/solid phase.

\section{Implications for soil remediation}

The cost to remediate soil contaminated by organic pollutants varies between different countries, but some estimates are: bioventing $\sim 100 € / \mathrm{tn}$, soil vapor extraction $\sim 100 € / \mathrm{tn}$, in situ thermal desorption $\sim 100-150 € /$ th, in situ oxidation $\sim 100-150 € /$ tn, ex situ bioremediation $\sim 100 € / \mathrm{tn}$, ex situ incineration cost $\sim 500-1000 € /$ tn (Khan et al. 2004). In the present study, a cylinder-toplane DBD reactor operating at atmospheric air pressure was used for the remediation of soil contaminated by liquid and solid organic pollutants. The experimental results revealed that the organic pollutants removal efficiency becomes respectable $(\sim 95 \%)$ at energy densities ranging from 4000 to $10000 \mathrm{~J} / \mathrm{g}$-soil, depending on the pollutants initial concentration (Figs. 2b, 3b). At very high initial pollutant concentration (i.e., $50 \mathrm{~g} / \mathrm{kg}$ soil) the energy density required is $\sim 10000 \mathrm{~J} / \mathrm{g}$-soil, which means that $1 \mathrm{kWh}$ is required to remediate $\sim 0.4 \mathrm{~kg}$ of polluted soil. At lower initial and more realistic pollutant concentration (i.e., $0.5 \mathrm{~g} / \mathrm{kg}$-soil), the energy density required is $\sim 4000 \mathrm{~J} / \mathrm{g}$-soil which means that $1 \mathrm{~kW} \mathrm{~h}$ is required to remediate $\sim 1.0 \mathrm{~kg}$ of polluted soil. In other words, the cost of soil remediation in a cylinder-to-plane DBD reactor ranges from 100 to $250 € /$ tn, depending on the pollutant initial concentration, indicating that DBD-based plasma could be a cost- effective oxidation technology for the treatment of soil contaminated by solid and liquid organic pollutants. Recently, a plane-to-grid DBD reactor has been tested for the removal of NAPL (i.e., mixture of $n$-decane, $n$ dodecane and $n$-hexadecane) from soil layers (Aggelopoulos et al. 2015b) where the cost was $\sim 20 € /$ tn ( $6.0 \mathrm{~kg}$-soil/kW h).

It is very important to point out that the reactor used in this study it is rather easy to be engineered despite its multidisciplinary character. Furthermore, this type of reactor can be very easily being up-scaled in order to be used for ex situ soil remediation. On the other hand, the penetration length of the produced active plasma species is normally short (up to $1-2 \mathrm{~cm}$ ) (Lu et al. 2014) and this factor has to be taken into account when DBD plasma is used for ex situ soil remediation. For in situ plasma-based soil remediation, other configurations have to be developed, where appropriately designed electrodes will be inserted in the soil so that the discharge will be ignited within the pore space and propagate in a multi-jet like form within the soil.

\section{Conclusion}

The removal of both 2,6 dichloropyridine and $n$-dodecane from soil layers in a cylinder-to-plane dielectric barrier discharge reactor, which operated at atmospheric air pressure, was investigated. As energy density risen, the removal efficiency increased, whereas when the initial pollutant concentration increased the removal efficiency dropped. The variance between the degradation rates of 2,6-dichloropyridine (solid pollutant) and $n$ - $\mathrm{C}_{12}$ (liquid pollutant) reflected the effect of pollutant state (solid or liquid) on removal efficiency. The remediation efficiency of both pollutants was lower for the loamy sandy soil than that of quartz sand, revealing the effect of soil heterogeneity and organic matter on removal efficiency. Finally, both pollutants were completely removed after 34 min of plasma treatment regardless of initial pollutant concentration and soil type, indicating that DBD-based plasma could be a well-promising oxidation technology for the ex situ treatment of soil contaminated by solid and liquid organic pollutants.

Acknowledgments This research has been co-financed by the European Union (European Social Fund-ESF) and Greek National Funds through the Operational Program "Education and Lifelong Learning" of the National Strategic Reference Framework (NSRF)-Research Funding Program: Supporting Postdoctoral 
Researchers. The author gratefully acknowledges use of the facilities of the Laboratoire de Génie des Procédés Plasmas et Traitements de Surfaces, Université Pierre et Marie Curie-Ecole Nationale Supérieure de Chimie de Paris. The author also acknowledges S. Cavadias, S. Ognier and C. Tsakiroglou for their helpful advices.

\section{References}

Aggelopoulos CA, Tsakiroglou CD (2008) The effect of microheterogeneity and capillary number on capillary pressure and relative permeability curves of soils. Geoderma 148:25-34

Aggelopoulos CA, Tsakiroglou CD (2009) A multi-flowpath model for the interpretation of immiscible displacement experiments in heterogeneous soil columns. J Contam Hydrol 105:146-160

Aggelopoulos CA, Tsakiroglou CD, Ognier S, Cavadias S (2015a) Non-aqueous phase liquid-contaminated soil remediation by ex situ dielectric barrier discharge plasma. Int $\mathrm{J}$ Environ Sci Technol 12:1011-1020

Aggelopoulos CA, Svarnas P, Klapa MI, Tsakiroglou CD (2015b) Dielectric barrier discharge plasma used as a means for the remediation of soils contaminated by non-aqueous phase liquids. Chem Eng J 270:428-436

Anotai J, Wuttipong R, Visvanathan C (2007) Oxidation and detoxification of pentachlorophenol in aqueous phase by ozonation. J Environ Manag 85:345-349

Bao X, Malik MA, Norton DG, Neculaes VB, Schoenbach KH, Heller R, Siclovan OP, Corah SE, Caiafa A, Inzinna LP, Conway KR (2014) Shielded sliding discharge-assisted hydrocarbon selective catalytic reduction of $\mathrm{NO}_{\mathrm{x}}$ over $\mathrm{Ag} / \mathrm{Al}_{2} \mathrm{O}_{3}$ catalysts using diesel as a reductant. Plasma Chem Plasma Process 34:825-836

Bocos E, Fernandez-Costas C, Pazos M, Sanroman MT (2015) Removal of PAHs and pesticides from polluted soils by enhanced electrokinetic-Fenton treatment. Chemosphere 125:168-174

Cai XD, Du WT, Wu JY, Li RF, Guo Y, Yang ZJ (2012) Effective treatment of trichloroethylene-contaminated soil by hydrogen peroxide in soil slurries. Pedosphere 22:572-579

Carroll KC, Oostrom M, Truex MJ, Rohay VJ, Brusseau ML (2012) Assessing performance and closure for soil vapor extraction: integrating vapor discharge and impact to groundwater quality. J Contam Hydrol 128:71-82

Hijosa-Valsero M, Molina R, Schikora H, Müller M, Bayona JM (2013) Removal of priority pollutants from water by means of dielectric barrier discharge atmospheric plasma. J Hazard Mater 262:664-673

Iya-Sou D, Laminsi S, Cavadias S, Ognier S (2013) Removal of model pollutants in aqueous solution by gliding arc discharge: determination of removal mechanisms. Part I: experimental study. Plasma Chem Plasma Process 33:97-113

Jamróz P, Gręda K, Pohl P, Zyrnicki W (2014) Atmospheric pressure glow discharges generated in contact with flowing liquid cathode: production of active species and application in wastewater purification processes. Plasma Chem Plasma Process $34: 25-37$

Jolibois J, Takashima K, Mizuno A (2012) Application of a nonthermal surface plasma discharge in wet condition for gas exhaust treatment: $\mathrm{NO}_{\mathrm{x}}$ removal. J Electrost 70:300-308

Khan FI, Husain T, Hejazi R (2004) An overview and analysis of site remediation technologies. J Environ Manag 71:95-122

Lladó S, Gràcia E, Solanas AM, Viñas M (2013) Fungal and bacterial microbial community assessment during bioremediation assays in an aged creosote-polluted soil. Soil Biol Biochem 67:114-123
Locke BR, Sato M, Sunka P, Hoffmann MR, Chang JS (2006) Electrohydraulic discharge and nonthermal plasma for water treatment. Ind Eng Chem Res 45:882-905

López-Vizcaíno R, Alonso J, Cañizares P, León MJ, Navarro V, Rodrigo MA, Sáez C (2014) Electroremediation of a natural soil polluted with phenanthrene in a pilot plant. J Hazard Mater 265:142-150

Lou J, Lu N, Li J, Wang T, Wu Y (2012) Remediation of chloramphenicol-contaminated soil by atmospheric pressure dielectric barrier discharge. Chem Eng J 180:99-105

Lu N, Lou J, Wang CH, Li J, Wu Y (2014) Evaluating the effects of silent discharge plasma on remediation of acid scarlet GRcontaminated soil. Water Air Soil Pollut 225:1991

Magureanu M, Mandache NB, Parvulescu VI (2015) Degradation of pharmaceutical compounds in water by non-thermal plasma treatment. Water Res 81:124-136

Malik MA, Kolb JF, Sun Y, Schoenbach KH (2011) Comparative study of NO removal in surface-plasma and volume-plasma reactors based on pulsed corona discharges. J Hazard Mater 197:220-228

Mirsal I (2008) Sources of soil pollution. Springer, Berlin, pp 137-173

Nilsson B, Tzovolou D, Jeczalik M, Kasela T, Slack W, Klint KE, Haeseler F, Tsakiroglou CD (2011) Combining steam injection with hydraulic fracturing for the in situ remediation of the unsaturated zone of a fractured soil polluted by jet fuel. J Environ Manag 92:695-707

Ognier S, Iya-sou D, Fourmond C, Cavadias S (2009) Analysis of mechanisms at the plasma-liquid interface in a gas-liquid discharge reactor used for treatment of polluted water. Plasma Chem Plasma Process 29:261-273

Ognier S, Rojo J, Liu Y, Duten X, Cavadias S, Thannberger L (2014) Mechanisms of pyrene degradation during soil treatment in a dielectric barrier discharge reactor. Plasma Process Polym 11:734-744

Ostapczuk A, Hakoda T, Shimada A, Kojima T (2008) Naphthalene and acenaphthene decomposition by electron beam generated plasma application. Plasma Chem Plasma Process 28:483-494

Pardo F, Rosas JM, Santos A, Romero A (2015) Remediation of soil contaminated by NAPLs using modified Fenton reagent: application to gasoline type compounds. J Chem Technol Biotechnol 90:754-764

Pironi P, Switzer C, Gerhard JI, Rein G, Torero JL (2011) Selfsustaining smoldering combustion for NAPL remediation: laboratory evaluation of process sensitivity to key parameters. Environ Sci Technol 45:2980-2986

Redolfi M, Makhloufi C, Ognier S, Cavadias S (2010) Oxidation of kerosene components in a soil matrix by a dielectric barrier discharge reactor. Process Saf Environ Prot 88:207-212

Stratton GR, Bellona CL, Dai F, Holsen TM, Thagard SM (2015) Plasma-based water treatment: conception and application of a new general principle for reactor design. Chem Eng J 273:543-550

Triplett Kingston JL, Dahlen PR, Johnson PC (2010) State-of-thepractice review of in situ thermal technologies. Ground Water Monit Remediat 30:64-72

Tzovolou D, Aggelopoulos C, Theodoropoulou M, Tsakiroglou C (2011) Remediation of the unsaturated zone of NAPL-polluted low permeability soils with steam injection: an experimental study. J Soils Sediments 11:72-81

Wang TC, Lu N, Li J, Wu Y (2010) Degradation of pentachlorophenol in soil by pulsed corona discharge plasma. J Hazard Mater 180:436-441

Wang T, Lu N, Li J, Wu Y, Su Y (2011a) Enhanced degradation of p-nitrophenol in soil in a pulsed discharge plasma-catalytic system. J Hazard Mater 195:276-280 
Wang TC, Lu N, Li J, Wu Y (2011b) Plasma-TiO 2 catalytic method for high-efficiency remediation of p-nitrophenol contaminated soil in pulsed discharge. Environ Sci Technol 45:9301-9307

Wang TC, Qu G, Li J, Liang D, Hu S (2014) Depth dependence of p-nitrophenol removal in soil by pulsed discharge plasma. Chem Eng J 239:178-184
Yu DY, Kang N, Bae W, Banks MK (2007) Characteristics in oxidative degradation by ozone for saturated hydrocarbons in soil contaminated with diesel fuel. Chemosphere 66:799-807

Zhang J, Liu J, Zhang R, Hou H, Chen S, Zhang Y (2015) Destruction of gaseous styrene with a low-temperature plasma induced by a tubular multilayer dielectric barrier discharge. Plasma Sci Technol 17:50-55 